\title{
Congenital Cyst Eye, One Clinical Case
}

\author{
Souhail H., Ifrkhas S., Laktaoui A.
}

Department of ophthalmology, Military hospital, Meknes Morocco, Faculty of medecine and pharmacy, fes Morocco

Email address:

souhail26@yahoo.fr (Souhail H.)

To cite this article:

Souhail H., Ifrkhas S., Laktaoui A.. Congenital Cyst Eye, One Clinical Case. Journal of Surgery. Vol. 3, No. 3, 2015, pp. 18-20. doi: $10.11648 /$ j.js.20150303.11

\begin{abstract}
Background: Congenital cyst eye is developmental abnormal arrangement of tissues .It is an extremely rare ocular malformation and is the rare cystic orbital lesion, usually evident at birth and has a varied presentation. A partial or complete failure in the involution of the primary optic vesicle resulting in the formation of a cyst. Case presentation: We report a case of unilateral congenital cystic eye, it was excised completely, and histopathology was confirmed the cystic nature of lesion. Conclusion: congenital cystic eye should be suspected in infants with an unrecognizable ocular globe. It is an extremely rare condition and with only 40 previous cases reported in the literature.
\end{abstract}

Keywords: Congenital, Cyst Eye

\section{Introduction}

Congenital cyst eye is developmental abnormal arrangement of tissues. It is an extremely rare ocular malformation and is the rare cystic orbital lesion, usually evident at birth and has a varied presentation. A partial or complete failure in the involution of the primary optic vesicle resulting in the formation of a cyst, with fewer than 40 cases reported. At the best of our knowledge, congenital cystic eye can be defined as a non-hereditary disorder of unknown origin. The disorder is most commonly unilateral, but bilateral congenital cystic eyeball has been recognized by Sacks et al. [1]. They investigated the central visual pathways in bilateral congenital cystic eye and evidenced that the intracranial portion of one optic nerve represented a remnant of the optic stalk and no chiasm was found. The malformation is usually present at birth or may become apparent later in childhood. The congenital cystic eye may be cystic or solid and the cyst may vary in size in relation to the patency of the stalk, and may be single or multiple. Connective tissue lined by neuroglial material composes the wall of the congenital cystic eye. The ocular structures derived from surface ectoderm, as lens or cornea, is lacking and the extra-ocular muscle surrounding the malformation may be normal or defective. Congenital cystic eye may be isolated or associated with intra or extra-ocular malformations [2]. The most common intraocular malformation described in association with congenital cystic eye is microphthalmia with cyst [3], as a rare entity cataloged on the spectrum of colobomatous eye disorders. Persistent hyperplastic primary vitreous in the fellow eye [4], dermal appendages [5], eyelid coloboma have been also recognized in association with congenital cystic eye. Systemic associations [6] include saddle nose, facial clefting, nostril malformation, choanal atresia, malformation of the sphenoid bone and other neurological abnormalities We report a case of unilateral congenital cystic eye, it was excised completely, and histopathology was confirmed the cystic nature of lesion.

\section{Case Report}

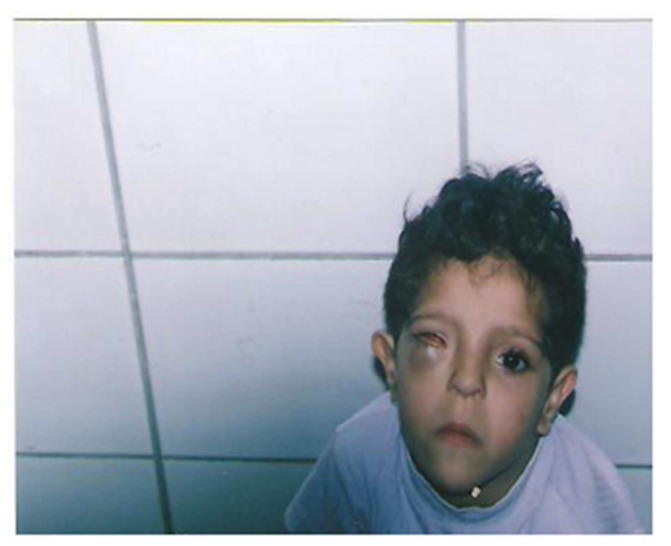

Figure 1. Presence of a mass swollen and blue in the lower right eyelid.

A 7 year old female child born with a congenital cyst eye. of non consanguinous parents. The examination find a fleshy 
mass in the right eye, the upper lid appeared ballooned and a reddish pink mass was bulging out (figure 1). The mass was soft, cystic in consistency, translucent, non tender, non pulsatile, non reducible. The left eye and Rest of the examination was normal. The patient underwent surgery. An anterior orbitotomy approach was used to excise the orbital mass while preserving the eyelids; histopathology confirmed the diagnosis. An orbital implant was also placed in the orbit keeping the future orbital growth in mind (figure 2, 3).

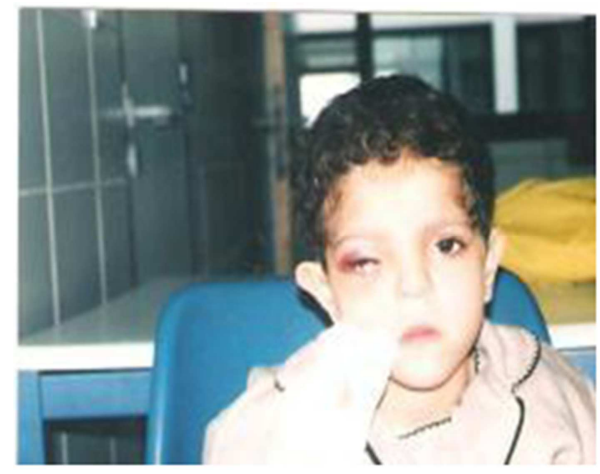

Figure 2. The appearance after ablation the mass.

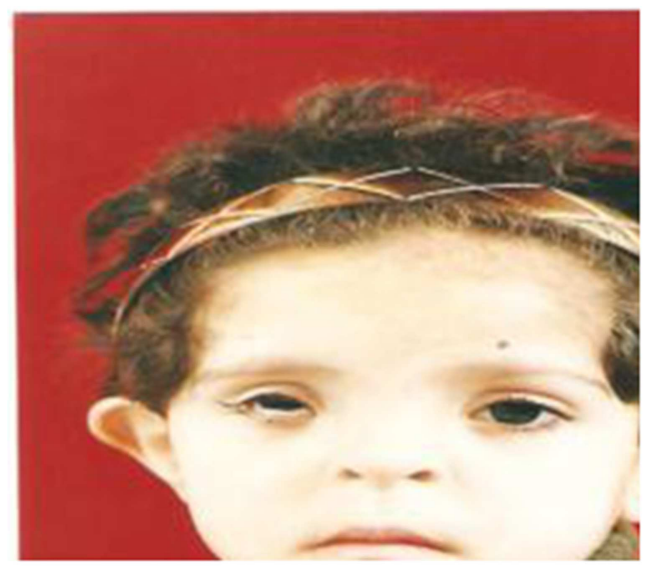

Figure 3. The appearance after the introduction of the provisional aesthetic prosthetic eye.

\section{Discussion}

The term congenital cystic eye was introduced by Ida Mann in 1937 for a cavity lined by neuroglial tissue [7]. It is an extremely rare ocular malformation and is the rare cystic orbital lesion $[8,9,10,11]$, usually evident at birth and has a varied presentation. Where the eye fails to develop correctly in utero and is replaced by benign, fluid-filled tissue. The exact aetiology of congenital cystic eye remains unknown $[10,11]$ genetic investigations performed in few cases have not yielded any peculiar defects $[12,13,14]$, the frequent presence of inflammatory cells in the cyst suggests an inflammatory cause $[10,11,15,16]$. It is thought to result from non invagination of the primary optic nerve vesicle between the $2 \mathrm{~mm}$ and $7 \mathrm{~mm}$ stages of the embryonic development [16], and ectodermal elements do not develop into the future eye structures. The orbit thus contains a cyst instead of an eye. The cyst is usually completely filled by proliferating glial tissue $[8,9,10,11]$. This abnormality is commonly unilateral as our case, though bilateral cases or microphthalmia with cyst of the fellow eye are described [8, $9,10]$.

There is no standardized protocol for management of the congenital cystic eye [14]. Surgical intervention is strongly advised in order to obtain an optimal cosmetic. Regarding timing of surgery, cystic globes have been excised within a week to several years after the birth. After excision, Chaudry et al. [17] achieved acceptable cosmesis by fitting prosthesis, while Mansour et al. [18] performed the excision of a congenital cystic eye at the age of seven months without the use of an implant and the conjunctional fornix was fitted with progressively larger spheres. Robb et al. [19] reported a case of congenital cystic eye in which an initial attempt for excision was followed by recurrence of the cyst in the orbit after three months. Based on their experience, they concluded that every effort should be made to totally excise the congenital cystic eye when surgical removal is undertaken, due to the risk of recurrence[14]. for us also the concern was cosmetic, after orbitotomy and excision the orbital mass we tried to preserving the eyelids and put the prosthetic eye.

The histologic appearance is variable from one case to another. The cyst is usually limited by a fibrous tissue dense, resembling the sclera, in which tissue muscle and fat are linked. The interior the cyst is bordered by immature retinal tissue $[8,9]$.

\section{References}

[1] Sacks JG, Lindenberg R. Efferent nerve fibers in the anterior visual pathways in bilateral congenital cystic eyeballs. Am J Ophthalmol. 1969; 68:691-695.

[2] Hayashi N, Repka MX, Ueno H, Iliff NT, Green WR. Congenital cystic eye: report of two cases and review of the literature. Surv Ophthalmol. 1999; 44:173-179.

[3] McLean CJ, Ragge NK, Jones RB, Collin JR. The management of orbital cysts associated with congenital microphthalmos and anophthalmos. $\mathrm{Br} \mathrm{J}$ Ophthalmol. 2003;87:860-863.

[4] Shastry BS. Persistent hyperplastic primary vitreous: congenital malformation of the eye. Clin Experiment Ophthalmol. 2009; 37:884-890.

[5] Tsitouridis I, Michaelides M, Tsantiridis C, Spyridi S, Arvanity M, Efstratiou I. Congenital cystic eye with multiple dermal appendages and intracranial congenital anomalies. Diagn Interv Radiol.2010;16:116-121

[6] Morselli PG, Morellini A, Sgarzani R, Ghi T, Galassi E. Congenital cystic eye: from prenatal diagnosis to therapeutic management and surgical treatment. J Craniofac Surg. 2011; $22: 360-363$.

[7] Mann I: A case of congenital cystic eye. Trans Ophtalmol Soc Aust 19391:120-124

[8] Rainer G, Rüdiger K, Wolfgang E. Congenital cystic eye. Graefe's Arch Clin Exp Ophthalmol. 2004, 242:268-271. 
[9] Marie-Laure R, Sophie L, Solange M, et al: Une lésion oculaire kystique congénitale exceptionnelle. Ann pathol 2007, 27: $59-60$

[10] Pillai AM, Rema M. Congenital cystic eye-A case report with CT scan. Indian J Ophthalmol 1987, 35(2): 88-91.

[11] Pankaj G, Krishna P, Ruchi G. Congenital cystic eye with multiple dermal appendages: a case Report. BMC Ophthalmology 2003, 3:7.

[12] Goldberg SH, Farber MG, Bullock JD, Crone KR, Ball WS: Bilateral congenital ocular cysts. Ophthalmic Paediatr Genet $1991,12: 31-38$

[13] Raina UK, Tuli D, Arora R, Mehta DK, Bansal R: Congenital cystic eyeball Ophthalmic Surg Lasers 2002, 33:262-263

[14] Cefalo MG, Colafati GS, Romanzo A, Modugno A, De Vito R, Mastronuzzi A Congenital cystic eye associated with a lowgrade cerebellar lesion that spontaneously regressed BMC
Ophthalmol. 2014 Jun 17; 14:80. doi: 10.1186/1471-2415-1480

[15] Duke-Elder, S. (1964): System of Ophthalmology Vol.111, Congenital Deformities. Part II, Henry Kimpton London, pp $451 \& 481$

[16] Gupta VP, Chaturvedi KU, Sen DK, Govekar KK Congenital cystic eyeball. Indian J Ophthalmol. 1990 Oct-Dec;38(4):2056.

[17] Chaudhry IA, Shamsi FA, Elzaridi E, Arat YO, Riley FC. Congenital cystic eye with intracranial anomalies: a clinicopathologic study. Int Ophthalmol. 2007; 27:223-233.

[18] Mansour AM, Li HK. Congenital cystic eye. Ophthal Plast Reconstr Surg. 1996; 12:104-107.

[19] Robb RM, Anthony DC. Congenital cystic eye: recurrence after initial surgical removal. Ophthalmic Genet. 2003; 24:117-123. 